\title{
COMMUNICATION
}

Cite this: DOI: $10.1039 / \times 0 \times x 00000 x$

\section{A Novel Regenerative Hydrogen Cerium Fuel Cell for Grid Energy Storage Applications}

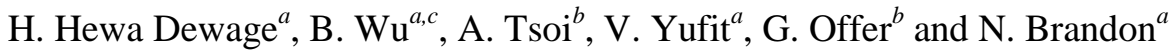

Received 00th January 2012,

Accepted 00th January 2012

DOI: $10.1039 / \times 0 \times x 00000 x$

www.rsc.org/

Energy storage is a key enabling technology that can significantly reduce the whole energy system cost of deploying large amounts of renewables. A novel hydrogen cerium redox flow battery is presented which has the potential to deliver both low cost and high performance. A $5 \mathrm{~cm}^{2}$ prototype is demonstrated, achieving $148 \mathrm{~mW} . \mathrm{cm}^{-2}$ when fully charged. Investigations demonstrated that the cerium charge transfer process was limiting the factor and improving this could increase the performance by an order of magnitude or more.

A global target has been set to reduce greenhouse gas emissions by $40 \%$ to $70 \%$ by 2050 compared to 2010 levels. ${ }^{1}$ However energy generation from renewable sources suffers from their intermittent and unreliable nature. Hence large-scale energy storage has become a vital technology in order to meet the set targets through the development of smart grids. ${ }^{2}$

Redox flow batteries (RFBs), like other electrochemical storage systems, have the ability to convert chemical energy into electrical energy; often referred to as reversible or regenerative fuel cells, they typically utilise two soluble redox couples contained in separate electrolyte tanks external to the battery system. Each electrolyte is

\footnotetext{
${ }^{a}$ Department of Earth Science and Engineering, Imperial College London, South Kensington Campus, London SW7 2AZ, UK.

E-mail:hmh311@imperial.ac.uk,

${ }^{b}$ Department Mechanical Engineering, Imperial College London, South Kensington Campus, London SW7 2AZ, UK.

${ }^{c}$ School of Design Engineering, Imperial College London, South Kensington Campus, London SW7 2AZ, UK.
}

pumped through their respective half-cell such that energy is stored/released as the RFB is charged/discharged. ${ }^{3}$ These two halfcells are separated by an ion exchange membrane that allows selective ions to pass from one electrolyte to another, with the electrons passing through an external circuit. ${ }^{4}$ The crucial requirements for grid level energy storage applications are all met by RFBs, namely fast response time ( milliseconds), site independence, low environmental footprint, high depth of discharge, high reliability, high round trip efficiency (ca. 85\%) and long life cycle (>>13000 cycles). ${ }^{5-7}$ Additionally, they are highly modular as the electrolyte volume and concentration determine the energy of the system, while the power depends on the stack size and the active surface area of each cell ${ }^{8}$, hence RFBs are used for a wide range of energy storage applications.

A large number of redox couples has been investigated in RFB research such as Fe/Cr, Poly-Sulphide/ $\mathrm{Br}_{2}, \mathrm{Zn} / \mathrm{Cl}_{2}, \mathrm{Zn} / \mathrm{Ce}$, allvanadium redox battery (VRB), V/Ce and $\mathrm{Zn} / \mathrm{Br}_{2} .{ }^{5}$ However, only the VRB and the $\mathrm{Zn} / \mathrm{Br}_{2}$ systems have been developed to a commercial level, and are currently exploited in applications such as load levelling, power quality control, and solar and wind deployment. ${ }^{9}$

Recent developments in RFB research has shown increasing interesting redox couple combinations that deliver high cell voltage and hence high energy density systems. ${ }^{10}$ Among them the cerium couple $\mathrm{Ce}(\mathrm{III}) / \mathrm{Ce}(\mathrm{IV})$ has been studied in several solvent compositions; the $\mathrm{Zn} / \mathrm{Ce} \mathrm{RFB}$ initially developed by Plurion Inc. (UK) in 2004 is one of the most popular. ${ }^{11-17}$ The cerium half-cell reaction as described in Equation (1) offers a high positive voltage of $1.72 \mathrm{~V}$ vs SHE, however, at such high potentials carbon based electrodes, which are typically used in RFBs, are no longer stable

\section{Broader context}

Energy storage is a key enabling technology that can significantly reduce the whole energy system cost of deploying large amounts of renewables. Electrochemical energy storage devices are one of the most efficient ways of converting and storing electrical energy. Out of many options, redox flow batteries (RFB) or regenerative fuel cells are one of the most promising for large scale energy storage, especially for high energy applications. Although a number of different chemistries have been explored, a major breakthrough is still required in order to fully deliver on their promise. In this work a novel chemistry, based upon hydrogen and cerium, is reported with the potential to deliver high energy density, low cost and high performance. The novel chemistry benefits from multi-electron transfer reactions and the use of alternative material to the typical carbon based electrodes. 
and undergo corrosion. ${ }^{13,18}$

In parallel to the development of RFBs, years of fuel cell development has led to the development of $\mathrm{H}_{2} /$ metal based RFBs where the hydrogen side is similar to the anode side of a proton exchange membrane fuel cell (PEMFC). The absence of crosscontamination is a major asset of these gas/liquid RFBs, meaning no permanent capacity loss through mixing of anolyte and catholyte. A modified PEMFC using hydrogen and $\mathrm{Fe}(\mathrm{III}) / \mathrm{Fe}(\mathrm{II})$ was investigated by Fatih et al. which later led to the development of a $\mathrm{H}_{2} / \mathrm{Fe}$ redox flow cell. ${ }^{19,20}$ Promising performance results have been reported on this system, with power densities of $270 \mathrm{mWcm}^{-2}$ and $257 \mathrm{mWcm}^{-2}$ for $1 \mathrm{M} \mathrm{FeSO}_{4}$ and $0.9 \mathrm{M}$ iron chloride with $0.9 \mathrm{M} \mathrm{HCl}$ solutions respectively. $^{20,21,21}$ In addition, a $\mathrm{H}_{2} / \mathrm{Br}_{2}$ system recently demonstrated a peak power density of $1400 \mathrm{mWcm}^{-2}$, making it a promising candidate, though concerns remain about the toxicity and associated safety issues in the case of bromine leakage. ${ }^{23}$ Another successful hydrogen based RFB was investigated by Yufit et al. which combines the $\mathrm{V}(\mathrm{IV}) / \mathrm{V}(\mathrm{V})$ couple from the popular VRB with a hydrogen anode; a promising initial study demonstrated power performance of $127 \mathrm{mWcm}^{-2}$ for an un-optimised system. ${ }^{24}$

Here we report a novel Regenerative Hydrogen-Cerium Fuel Cell (RHCFC) which combines the high voltage cerium redox couple with the hydrogen generation reaction, usually considered as parasitic in other systems. ${ }^{25}$

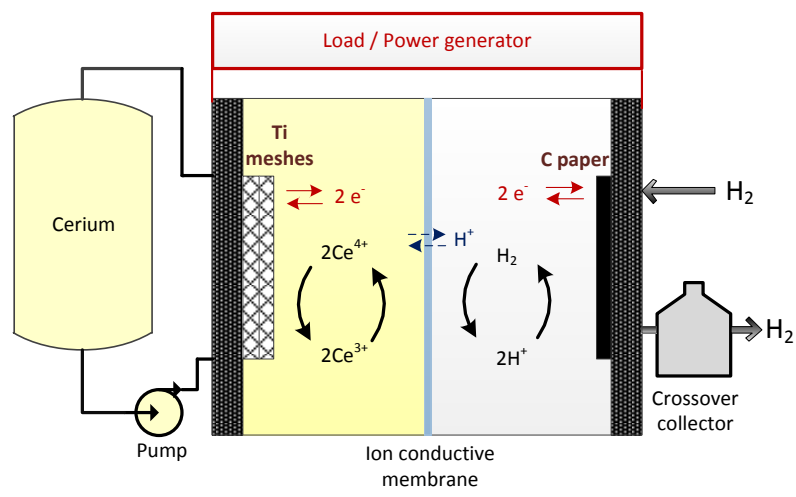

Figure 1: Schematic illustration of the RHCFC.

As represented in Figure 1, a solution of $\mathrm{Ce}(\mathrm{III}) / \mathrm{Ce}(\mathrm{IV})$ is pumped through the cathode whereas hydrogen is passed through the anode. The cathode and anode are separated by a cation exchange membrane that allows protons to pass through while electrons pass through an external circuit. When the cell is in energy delivery mode (discharging) cerium (IV) is reduced to cerium (III) whereas hydrogen is oxidised to protons as described in Equations (1-3):

$$
\begin{aligned}
& \text { Cathode: } 2 \mathrm{Ce}^{4+}+2 e^{-} \rightarrow 2 \mathrm{Ce}^{3+}, \mathrm{E}_{\text {cathode }}^{0}=1.72 \mathrm{~V} \text { vs SHE } \\
& \text { Anode: } \mathrm{H}_{2} \rightarrow 2 \mathrm{H}^{+}+2 e^{-}, E_{\text {anode }}^{0}=0 \mathrm{~V} \text { vs SHE } \\
& \text { Overall: } 2 \mathrm{Ce}^{4+}+\mathrm{H}_{2} \rightarrow 2 \mathrm{Ce}^{3+}+2 \mathrm{H}^{+}, \quad E_{\text {cell }}^{0}=1.72 \mathrm{~V} \text { vs SHE }
\end{aligned}
$$

The experiments were carried out using a single cell assembly that had a $5 \mathrm{~cm}^{2}$ active area as displayed in Figure 1. Two superimposed platinised titanium meshes (METAKEM G, $700 \mu$ m thick each) were used as electrodes on the cathode side and a platinised carbon based electrode (Johnson Matthey, $200 \mu \mathrm{m}$ ) was used on the anode. The two electrodes were separated by a Nafion® 117 membrane. The electrolytes were pumped through serpentine graphite flow channel plates (SGL PPG85 graphite plates) that also served as current collectors. A plastic based insulating layer (RS polypropylene sheet) was sandwiched by aluminium end plates in order to provide a uniform pressure distribution to the cell. Viton gaskets were used between the different layers of the cell to provide a good seal. Finally a crossover collector was connected to the hydrogen outlet to collect any liquid electrolyte crossing to the gas side. ${ }^{26}$

A cerium solution $(50 \mathrm{~mL})$ of $0.5 \mathrm{M}$ was prepared by adding $5.75 \mathrm{~g}$ of Ce (III) carbonate (Sigma-Aldrich) to $38 \mathrm{~mL}$ of deionised water and then dissolving the stirred mixture by slowly adding $12 \mathrm{~mL}$ of concentrated methanesulfonic (MSA) acid (Sigma-Aldrich) until a clear Ce (III) solution was obtained. The final concentration of MSA was 4M. Using a peristaltic pump (Cole Palmer 77200-50) the catholyte was pumped at $48-146 \mathrm{~mL} / \mathrm{min}$ depending on the experiment, whereas the hydrogen was flowing through the anode at constant $50 \mathrm{~mL} / \mathrm{min}$ in all experiments.

Galvanostatic charge/discharge curves were recorded using an Autolab PGSTAT30 with a 10A current booster (Autolab BSTR10A) running NOVA 1.9 software. Measurements were made using a 4-electrode set-up to minimise contact resistance losses of the measurement probes. The hydrogen flow rate was controlled using a Bronkhorst (EL-FLOW) mass flow controller. Figure 2 shows the charge/discharge characteristics of the RHVFC. The upper and lower voltage limits were set to $1.8 \mathrm{~V}$ and $1.5 \mathrm{~V}$ respectively as calculated through the Nernst equation (Equation 4) assuming 0.495 and $0.005 \mathrm{M}$ concentration of $\mathrm{Ce}(\mathrm{IV})$ and $\mathrm{Ce}(\mathrm{III})$ respectively.

$\mathbf{E}_{\text {cell }}=E_{\text {cell }}^{0}+\frac{R T}{F} \ln \frac{\left[C e^{4+}\right]\left(P_{H_{2}}\right)^{0.5}}{\left[\mathrm{Ce}^{3+}\right]\left[\mathrm{H}^{+}\right]}$

Between experiments, the cell was held at the limits of potential until the current dropped to $<2 \mathrm{~mA} / \mathrm{cm}^{2}$ in order to measure charge/discharge curves from the same datum. This procedure was not carried out at $5 \mathrm{~mA} / \mathrm{cm}^{2}$, as the overpotential was so low, the current would drop below the cut-off current density straight away; hence the efficiency calculations were made at this current density. Both, the coulombic efficiency (CE) defined as the ratio of the discharge capacity over the charge capacity, and the voltage efficiency (VE) defined as the average voltage during discharge over the average voltage during charge, were equal to $94 \%$. Thus the energy efficiency (EE), which is the product of CE and VE, was calculated to be $88 \%$, a promising result for the first generation of RHCFC.

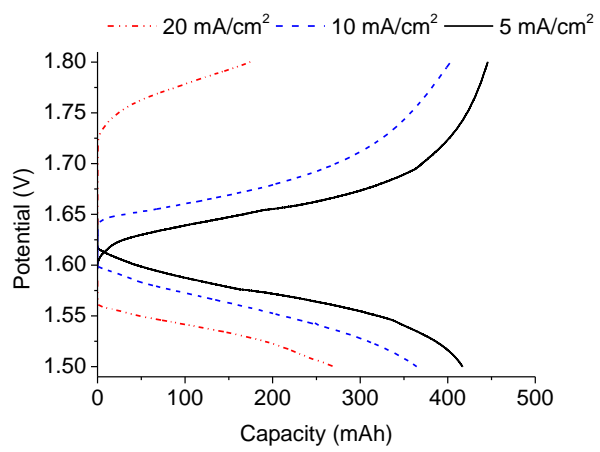

Figure 2: Galvanostatic charge/discharge curves of the RHCFC with a hydrogen flow rate of $50 \mathrm{ml} / \mathrm{min}$ and cerium flow rate of 97 $\mathrm{ml} / \mathrm{min}$ at different current densities.

Observations of the charge/discharge behaviour in Figure 2 shows an asymmetry between the charge and discharge processes, with more available capacity under charge than discharge at low current densities suggesting that the charge kinetics are faster than the discharge. However, the opposite is true at higher current densities, suggesting that mass transport losses are more significant for the charging processes. 
A

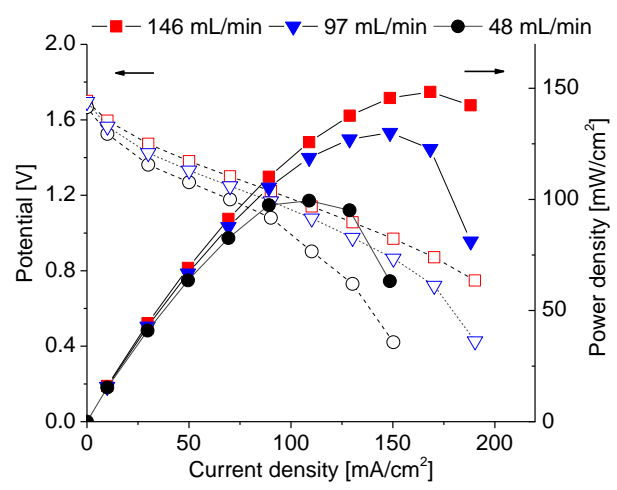

B

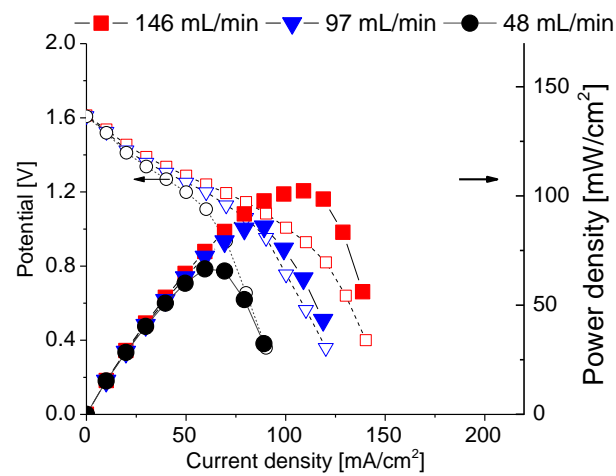

Figure 3: Power curve data taken at A) $100 \%$ and B) $50 \%$ SOC for different cerium flow rates and at $50 \mathrm{~mL} / \mathrm{min}$ flow rate for hydrogen.

Power curve data was also taken by applying repeating charge and discharge pulses of $10 \mathrm{~s}$ with a $30 \mathrm{~s}$ rest in between. This ensured that the state-of-charge (SOC) remained relatively constant during the measurements, and also that concentration gradient from one pulse did not affect the next. The $100 \%$ SOC was defined by the fully charged cell at $5 \mathrm{~mA} / \mathrm{cm}^{2}$.

Analysis of the power curve data showed that a peak power density of $148 \mathrm{~mW} / \mathrm{cm}^{2}$ was achieved at a flow rate of $146 \mathrm{~mL} / \mathrm{min}$. It can be seen that at $100 \% \mathrm{SOC}$, at a cerium flow rate of $97 \mathrm{~mL} / \mathrm{min}(1.5$ times smaller) the maximum power density drops by $12 \%$ to 130 $\mathrm{mW} / \mathrm{cm}^{-2}$. At the flow rate of $48 \mathrm{~mL} / \mathrm{min}$ (3 times less), the peak power density dropped by $32 \%$ to $100 \mathrm{~mW} / \mathrm{cm}^{-2}$. A similar behaviour was observed at 50\% SOC : at 97 and $48 \mathrm{~mL} / \mathrm{min}$ flow rates a peak power density drop of $16 \%$ and $34 \%$ were respectively observed compared to the peak power density achieved at 146 $\mathrm{mL} / \mathrm{min}$. Therefore, the peak power is a clearly a function of the cerium flow rate, indicating mass transport limitations. It also demonstrates that a reduction of the cerium flow rate can have a larger detrimental effect on the RHCFC performance than a decrease in SOC.

A

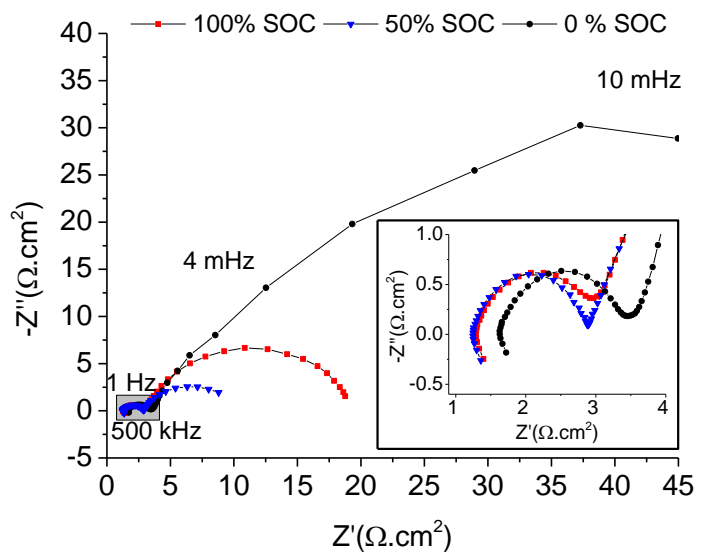

B

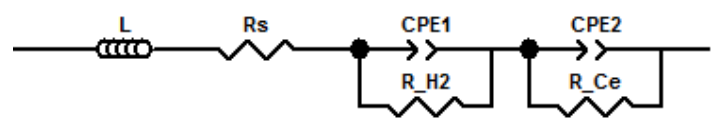

Figure 4: A) Nyquist representation of EIS measurements at different SOCs with a hydrogen flow rate of $50 \mathrm{~mL} / \mathrm{min}$ and cerium flow rate of $146 \mathrm{~mL} / \mathrm{min} \mathrm{B}$ ) equivalent circuit used in order to fit the EIS data.

Electrochemical Impedance Spectroscopy (EIS) measurements were taken from the cell at $100 \%, 50 \%$ and $0 \%$ SOC. Measurements were made with a current RMS of $50 \mathrm{~mA}$ over a frequency range of 500 $\mathrm{kHz}$ to $0.01 \mathrm{~Hz}$. Figure $4 \mathrm{~A}$ presents a typical EIS response of the RHCFC at different SOC. The Nyquist plots in Figure 4A displays two depressed semi-circles at all SOC, indicating the presence of at least two different processes in the RHCFC.
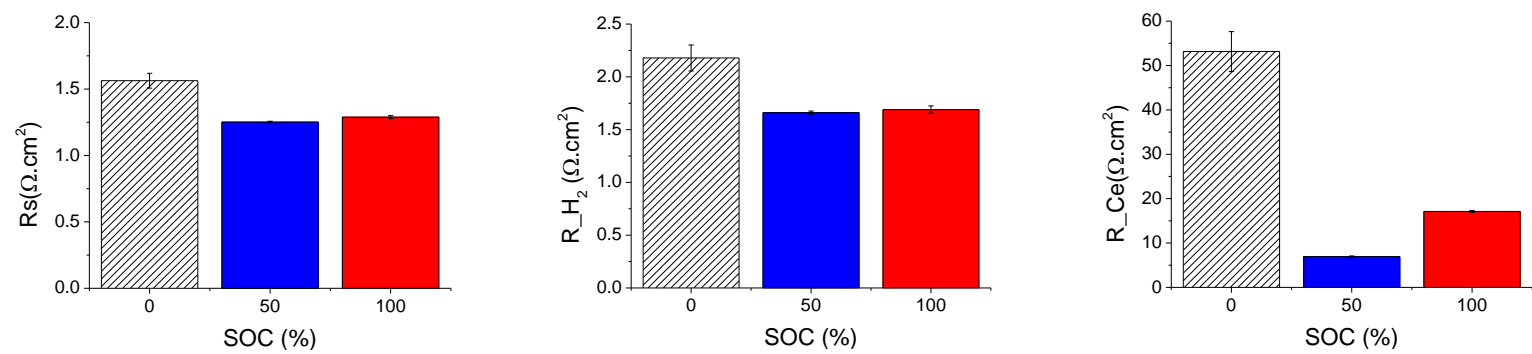

Figure 5: A) Series, B) Hydrogen charge transfer and C) Cerium charge transfer resistance at different SOCs for a hydrogen flow rate of $50 \mathrm{~mL} / \mathrm{min}$ and cerium flow rate of $146 \mathrm{~mL} / \mathrm{min}$. 
While the shape of the EIS spectra appears to be similar at higher frequencies, the resistance at lower frequencies is considerably larger in the fully discharged state. In order to extract quantitative information from the EIS measurements, the data was fitted to the equivalent circuit shown in Figure 4B using ZView software. In this circuit, the inductor $\mathrm{L}$ and the resistance Rs represent the inductive response of the electronically conductive components in the cell including current probes and wires and series resistance of both electronic and ionic conductive components of the RHCFC respectively. The second element, comprising the constant phase element CPE1 and the parallel resistance $\mathrm{R}_{-} \mathrm{H}_{2}$, is attributed to the charge transfer resistance associated with the hydrogen side; this was confirmed after further EIS experiments were carried out at different cerium flow rate where the first semi-depressed circle remained unchanged while the second varied. Therefore the symmetrical third element comprising CPE2 and R_Ce is attributed to the charge transfer losses associated to the cerium side. From the values of the fitted data (Figure 5A, B and C), the series resistance appears to be similar between 50 and $100 \%$ SOC with only a decrease of $3 \%$ from 100 to $50 \%$ SOC. The charge transfer resistance of the hydrogen side shows an analogous behaviour where there is only a decrease of $2 \%$ from 100 to $50 \%$ SOC. However at $0 \%$ SOC the series resistance and the charge transfer resistance of the hydrogen side, is higher by 21 and $29 \%$, respectively in comparison to $100 \%$ SOC. According to the Nernst equation of the RHCFC (Equation 4), the acid concentration varies from $3 \mathrm{M}$ at $100 \% \mathrm{SOC}$ to $4 \mathrm{M}$ at $0 \%$ SOC. The higher level of acid concentration in the bulk solution could lead the Nafion membrane to uptake MSA leading to a decrease of its water content which will affect proton mobility as similar behaviour has been observed for Nafion membrane in a sulphuric acid environment. ${ }^{27}$ This could explain why the MSA concentration would affect both the series resistance and charge transfer resistance of the hydrogen electrode. Finally, looking at the charge transfer resistance of the cerium electrode (Figure 5C), a "U" shape pattern is observed where the losses are the lowest at $50 \%$ SOC which is expected as no one reactant is depleted more than the other. In comparison to the resistance of $6.9 \Omega \mathrm{cm}^{-2}$ at $50 \% \mathrm{SOC}$ it rises to $17.1 \Omega . \mathrm{cm}^{-2}$ at $100 \%$ SOC and to $53.2 \Omega . \mathrm{cm}^{-2}$ at $0 \%$ SOC. The threefold difference in resistance between the fully charged and discharged state highlights further the asymmetry in this cell that has also been demonstrated through cyclic voltammetry experiments in literature. ${ }^{11}$ Furthermore it is also believed that the increase in resistance is also partially due to the lack of proton mobility in the membrane. It is clear from these results that the overall resistance in the cell is largely dominated by the charge transfer losses on the cathode as they are a factor of 10-35 times larger than other source of losses.

\section{Conclusions}

The feasibility of a novel regenerative fuel cell combining hydrogen with the $\mathrm{Ce}^{3+/} \mathrm{Ce}^{4+}$ redox couple has been demonstrated. Successful charge and discharge at different current densities was carried out. A peak power density of $148 \mathrm{~mW} / \mathrm{cm}^{2}$ was achieved at $100 \%$ SOC and its value decreases rapidly with decreasing cerium flow rate. These experiments demonstrated the asymmetry between the charge and discharge processes, where the charging step is mass transport limited which explains the high dependence of the performance on the cerium flow rate. Moreover EIS data confirmed that the cell is ultimately limited by the losses on the cerium side where the resistance is far worse at $0 \%$ SOC than at $100 \%$. It also shows that the series resistance and the charge transfer resistance of the anode is higher at $0 \%$ SOC as the concentration of MSA is higher perhaps leading to reduced mobility of protons in the membrane. However in order to validate these initial conclusions, further work is necessary where half-cell information should be gained in order to decouple the anode and cathode processes. Furthermore it is clear that this cell was built as a proof of concept. Future designs should not permit carbon based materials to come in contact with the cerium electrolyte as this leads to carbon corrosion due to the high operating potential.

\section{Notes and references}

1. IPCC Fifth Assessment Synthesis Report: Approved Summary for Policymakers, 2014.

2. G. Strbac, M. Aunedi, D. Pudjianto, P. Djapic, and F. Teng, Strategic Assessment of the Role and Value of Energy Storage Systems in the UK Low Carbon Energy Future Report for Carbon Trust, 2012.

3. M. Bartolozzi, J. Power Sources, 1989, 27, 219-234.

4. P. Alotto, M. Guarnieri, and F. Moro, Renew. Sustain. Energy Rev., 2014, 29, 325-335.

5. M. Skyllas-Kazacos, M. H. Chakrabarti, S. a. Hajimolana, F. S. Mjalli, and M. Saleem, J. Electrochem. Soc., 2011, 158, R55.

6. S. Eckroad, Handbook of Energy Storage for Transmission or Distribution Applications., California (USA), 2002.

7. C. Ponce de León, A. Frías-Ferrer, J. González-García, D. A. Szánto, and F. C. Walsh, J. Power Sources, 2006, 160, 716-732.

8. M. Rychcik and M. Skyllas-Kazacos, J. Power Sources, 1988, 22, 59-67.

9. K. C. Divya and J. Østergaard, Electr. Power Syst. Res., 2009, 79, 511-520.

10. P. Leung, X. Li, C. Ponce de León, L. Berlouis, C. T. J. Low, and F. C. Walsh, RSC Adv., 2012, 2, 10125.

11. P. K. Leung, C. Ponce de León, C. T. J. Low, and F. C. Walsh, Electrochim. Acta, 2011, 56, 2145-2153.

12. B. Fang, Electrochim. Acta, 2002, 47, 3971-3976.

13. Z. Xie, Q. Liu, Z. Chang, and X. Zhang, Electrochim. Acta, 2013, 90, 695-704.

14. Z. Xie, D. Zhou, F. Xiong, S. Zhang, and K. Huang, J. Rare Earths, 2011, 29, 567-573.

15. P. K. Leung, C. Ponce-de-León, C. T. J. Low, A. A. Shah, and F. C. Walsh, J. Power Sources, 2011, 196, 5174-5185.

16. R. L. Clarke, B. J. Dougherty, S. Harrison, P. J. Millington, and S. Mohanta, 2004.

17. R. L. Clarke, B. J. Dougherty, S. Harrison, P. J. Millington, and S. Mohanta, 2006.

18. M. H. Chakrabarti, N. P. Brandon, S. A. Hajimolana, F. Tariq, V. Yufit, M. A. Hashim, M. A. Hussain, C. T. J. Low, and P. V. Aravind, J. Power Sources, 2014, 253, 150-166.

19. K. Fatih, D. P. Wilkinson, F. Moraw, A. Ilicic, and F. Girard, Electrochem. Solid-State Lett., 2008, 11, B11.

20. M. Alon, A. Blum, and E. Peled, Feasibility study of hydrogen/iron redox flow cell for grid-storage applications, 2013, vol. 240.

21. M. C. Tucker, K. T. Cho, and A. Z. Weber, J. Power Sources, 2014, 245, 691-697.

22. M. C. Tucker, V. Srinivasan, P. N. Ross, and A. Z. Weber, J. Appl. Electrochem., 2013, 43, 637-644.

23. K. T. Cho, P. Ridgway, A. Z. Weber, S. Haussener, V. Battaglia, and V. Srinivasan, J. Electrochem. Soc., 2012, 159, A1806-A1815.

$24 . \quad$ V. Yufit, B. Hale, M. Matian, P. Mazur, and N. P. Brandon, J. Electrochem. Soc., 2013, 160, A856-A861.

25. A. A. Shah, H. Al-Fetlawi, and F. C. Walsh, Electrochim. Acta, $2010, \mathbf{5 5}, 1125-1139$.

26. K. T. Cho, M. C. Tucker, M. Ding, P. Ridgway, V. S. Battaglia, V. Srinivasan, and A. Z. Weber, Chempluschem, 2014, n/a-n/a.

27. Z. Tang, R. Svoboda, J. S. Lawton, D. S. Aaron, A. B. Papandrew, and T. A. Zawodzinski, J. Electrochem. Soc., 2013, 160, F1040F1047. 